\title{
SIGNIFICADO CLÍNICO-PATOLÓGICO DAS EXPRESSÕES CIITOFOTOMÉTRICAS DO KI-67 E CASPASE-3 NO CARCINOMA DE CÉLULAS ESCAMOSAS DO ESÔFAGO
}

\section{Clinicopathologic significance of the Ki-67 and Caspase-3 cytophotometric expres- sions in the esophageal squamous cell carcinomal}

Gilmar Pereira SILVA, Osvaldo MALAFAIA, Ronaldo Máfia CUENCA Jurandir Marcondes RIBAS-FILHO, Paulo Afonso Nunes NASSIF, Carmen Australia Paredes Marcondes RIBAS, Jorge Luiz de Matos ZEVE

ABCDDV/597

Silva GP, Malafaia O, Cuenca RM, Ribas-Filho JM, Nassif PAN, Ribas CAPM, Zeve JLM. Significado clínico-patológico das expressões citofotométricas do Ki-67 e Caspase-3 no carcinoma de células escamosas do esôfago. ABCD Arq Bras Cir Dig. 2008;21(2):77-84

RESUMO - Racional - A escolha da forma de tratamento do carcinoma de células escamosa de esôfago ainda hoje é orientada pelo estadiamento tumoral, onde as características histopatológicas do tumor são o maior determinante. Parale-lamente, desenvolvem-se estudos para entender o comportamento da biologia tumoral por método imunoistoquímico de quantificação manual, avaliando a ati-vidade proliferativa ou apoptótica do tecido em análise. As desvantagens conti-das no modo manual fizeram surgir e desenvolver método computadorizado de análise de imagem. Objetivos - Verificar as expressões dos marcadores KI-67 e Caspase-3 e correlacioná-las com as características clínico-patológicas do tumor. Métodos - Foram estudados 29 blocos parafinados provenientes de pa-cientes portadores de carcinoma de células escamosas de esôfago submetidos à esofagectomia e pertencentes a acervos de laboratórios de patologia. Proce-deu-se preparo das lâminas por técnica imunoistoquímica convencional. A quantificação da imunorreatividade às proteínas Ki-67 e Caspase-3 foi realizada pelo software de análise de imagem computadorizada SAMBA (Systeme d'Analyse Microphotometrique a Balayage Automatique) através do índice de marcagem encontrado. Resultados - Predominaram na amostra o sexo masculino (82,7\%); maiores de 50 anos; tumores moderadamente diferenciados (68,98\%); estágio III (72,42\%); lesões $>3 \mathrm{~cm}$ e localizadas no $1 / 3$ inferior do ór-gão. Os índices médios de marcagem identificados foram de 62,05\% para o Ki-67 e 86,06\% para a Caspase-3, e não mostraram correlação com as caracterís-ticas clínico-patológicas como sexo, idade, estadiamento tumoral, grau de pro-fundidade da lesão e comprometimento linfonodal. Houve significante diferença de expressão do Ki-67 entre os graus histológicos $(P=0,047)$ e correlação entre os índices dos marcadores estudados $(\mathrm{r}=0,41$ e $\mathrm{P}=0,032)$. Conclusão - Na presente investigação as atividades das proteínas estudadas se mostraram in-tensas sendo que a da Caspase-3 foi superior ao Ki-67 mas sem correlação com as características clínico-patológicas.

DESCRITORES - Ki-67. Caspase-3. Citometria de imagem. Neoplasia do esôfago.

\section{INTRODUÇÃO}

O câncer de esôfago é neoplasia freqüente, ocupando o oitavo lugar em incidência e a sexta causa de morte no mundo ${ }^{7}$. Apesar dos recentes esforços para melhorar a sobrevida dos pacientes, até o presente o prognóstico é ruim, devido ao diagnóstico tardio e ineficácia do tratamento, resultando em taxa de sobrevida em cinco anos menor que $10 \%{ }^{4}$.

A etiologia é multifatorial, ressaltando-se os diferentes fatores tais como exposição ambiental, hábitos dietéticos, irritação crônica da mucosa, infecção, influências culturais e predisposição genética ${ }^{14}$.

Destes, os que estão mais comprovadamente relacionados à carcinogênese são os efeitos sinérgicos do uso

Trabalho realizado na União Educacional do Planalto Central, UNIPLAC, Brasília, DF, Brasil

Endereço para correspondência: Gilmar Pereira Silva, e-mail ipem@evangelico.org.br abusivo do álcool e fumo com risco diretamente relacionado à duração e quantidade de uso, fazendo o conjunto das pessoas com esses hábitos o grupo de maior risco para os habitantes do mundo ocidental.

Mais da metade dos pacientes com carcinoma de células escamosas de esôfago (CCEE), apresenta-se no momento do diagnóstico em estágio da doença localmente avançada ou já com metástases à distância, tendo em vista que a principal manifestação, a disfagia, passa a se manifestar quando há comprometimento de pelo menos $75 \%$ da luz do órgão ${ }^{21}$.

Para reduzir a dimensão do problema, o diagnóstico precoce seria necessário e a realização de exames periódicos em populações e áreas de risco se faz re-comendável.

Os avanços da medicina moderna sinalizam em direção da aplicação dos novos conhecimentos da biologia molecular no entendimento da carcinogênese. Das inúmeras proteínas reguladoras do ciclo celular, cerca de 28 estão implicadas na carcinogênese do tumor de esôfago por diferentes mecanismos, interferindo direta ou 
indiretamente na fisiologia normal da replicação celular. A identificação destas proteínas comumente é feita por marcação imunoistoquímica, com quantificação manual ou automática, onde são estudados parâmetros de biologia tumoral de interesse clínico, como a atividade proliferativa celular ou vascular, atividade apoptótica e estado de adesão intercelular ${ }^{27}$.

No tecido esofágico, a atividade proliferativa pode ser expressa por meio da identificação de proteínas específicas e por análise do conteúdo de ácido desoxirribonucléico (ADN). Podem ser mensurados por métodos automatizados ou semi-automatizado, como as citometrias de fluxo e de imagem ou por método manual que utiliza a experiência individual e subjetividade do observador.

Os objetivos deste estudo foram: 1. determinar pelo sistema SAMBA de citofotometria de imagem os índices médios das expressões do Ki-67 e Caspase-3 em amostras de CCEE e 2. correlacionar os índices obtidos com os dados clínicos e histopatológicos das amostras.

\section{MÉTODOS}

Este estudo foi retrospectivo com delineamento tipo transversal não controlado. A amostra constou de 29 blocos de parafina contendo CCEE preparados a partir de peças cirúrgicas produto de esofagectomias em serviços de cirurgia entre os anos de 1995 e 2005 . Estes blocos foram provenientes de pacientes registrados, diagnosticados e pertencentes aos arquivos dos serviços de anatomia patológica dos seguintes hospitais: Hospital Regional do Gama/Brasília - HRG/DF (sete casos); Hospital das Forças Armadas/Brasília - HFA/DF (cinco casos); Hospital Brasília/ Brasília - HB/DF (dois casos) e Hospital São Marcos/ Teresina - HSM/TE (15 casos) e seu uso aprovado por comitê de ética em pesquisa.

Visando melhor uniformização da amostra, foram estabelecidos os seguintes critérios de inclusão: 1. portadores de CCEE de histologia característica; 2. livres de tratamentos prévios (quimioradioterapia); 3. material biológico proveniente de peça cirúrgica; 4 . amostra tumoral representativa no bloco de parafina para que se pudes-se obter pelo menos três cortes; 5 . material de boa qualidade e em bom estado de preservação.

De cada paciente foi extraído um conjunto de informações que incluiu: 1. dados identificativos e administrativos; 2. dados clínicos, idade, sexo; 3. dados histopatológicos e grau de diferenciação tumoral segundo a OMS (a - bem diferenciado $(\mathrm{G} 1), \mathrm{b}$ - moderadamente diferenciado $(\mathrm{G} 2)$, c- pouco diferenciado (G3), d - indiferenciado (G4); 4. estadiamento tumoral de I a IV, segundo a UICC/ TNM; 5. tamanho tumoral em $<3 \mathrm{~cm}$ e $>3 \mathrm{~cm} ; 6$. localização em $1 / 3$ superior, $1 / 3$ médio e $1 / 3$ inferior

Cada bloco parafinado foi submetido à microtomia para obtenção de três cortes com espessura de $3 \mu \mathrm{m}$ cada, os quais foram distribuídos da seguinte forma: o primeiro para imunoistoquímica com anticorpo anti-Ki-67; o segundo, para o anticorpo anti-Caspase-3; e o terceiro, para coloração com hematoxilina e eosina com a finalidade de validação diagnóstica realizada por dois patologistas.

Todos os casos foram submetidos à técnica da imunoistoquímica para a investigação da presença das proteínas Ki-67, Caspase-3, utilizando o protocolo dos laboratórios dos serviços de patologia do Hospital Universitário Evangélico de Curiti-ba e Laboratório Citolab de Curitiba.

O sistema SAMBA 4000 (Systéme d'Analyse Microscopique à Balayage Automatique / Sistema de Análise Microscópica de Busca Automática - Alcatel - Grenoble, França), destinado a fazer a leitura citofotométrica das lâminas era constituído por um hardware, capaz de captar imagens microscópicas, e por um software próprio (Immuno) para interpretar e analisar as imagens captadas, permitindo contar a quantidade total dos núcleos ou citoplasmas coloridos imunomarcados.

As imagens processadas eram digitalizadas em pixels. Este processo confere um valor para cada ponto-imagem (pixel). A luz absorvida pelo tecido em cada segmento era quantificada. A quantificação da luz absorvida era expressa através de uma escala de variações de níveis de cinza que vai de 0 (preto) a 255(branco). Este processo corresponde à numerização da imagem que envolve duas etapas: geração da matriz em tons cinza e transformação desta em matriz numérica binária.

A leitura foi feita nas lâminas analisando-se células imunopositivas para os anticorpos contra Caspase-3 e Ki-67. Foi realizada com duas repetições em campos definidos e escolhidos aleatoriamente de área com imagem visual de melhor imunomarcação (hot-points / zonas quentes) e captados por microscopia óptica em aumento de 400x. Foi considerada positiva a imunomarcação somente em núcleo, na cor castanha, quando se identificava o marcador Ki-67. A cor acastanhada e de localização citoplasmática, identificava o marcador Caspase-3, independente da intensi-dade da coloração, diferenciava entre positivo e negativo. Foram examinadas pelo menos 1000 células nos campos selecionados e processados pelo sistema de análise de imagem.

Nas lâminas foi analisado o índice de marcagem, que representa a percentagem de área tecidual especificamente marcada pela prova glicoistoquímica. Ele para o Ki-67 representa a razão paramétrica absoluta entre os núcleos de células positivas e o total de células tumorais contadas. Para Caspase-3, a razão paramétrica absoluta entre os áreas imunomarcadas e a total celular mensurado nas células tumorais contadas.

Os controles foram casos de câncer mamário com intensa imunomarcação para ambos os antígenos deste estudo, quantificados em 200 células tumorais selecionadas pelos mesmos critérios das células tumorais em estudo.

Os resultados foram expressos por médias, medianas, valores mínimos, valores máximos e desvios-padrão. Para as variáveis categóricas, os resultados foram expressos por frequências e percentuais. A condição de normalidade das variáveis quantitativas foi investigada usando-se o teste de Shapiro-Wilks.

Para a comparação de dois grupos em relação à expressão dos marcadores foi usado o teste $t$ de Student 
para amostras independentes ou o não-paramétrico de Mann-Whitney, quando apropriado. A comparação entre três grupos foi feita usando-se o teste não-paramétrico de Kruskal-Wallis. Para avaliar o grau de associação en-tre a expressão dos marcadores, foi estimado o coeficiente de correlação de Pear-son ou o coeficiente de correlação de Spearman. Todos os testes foram realizados no SPSS, de forma bi-caudal e admitindo-se como estatisticamente significativos os valores de $\mathrm{P}$ menores que 0,05 .

\section{RESULTADOS}

Demograficamente o sexo masculino predominou com $82,7 \%$ e idade de $58,7 \pm 7,7$.

Quanto ao grau de diferenciação celular, houve predominância do moderadamente diferenciado $(\mathrm{G} 2=68,98 \%)$ em relação aos bem $(\mathrm{G} 1=20,69 \%)$ e pouco dife-renciados $(\mathrm{G} 3=10,43 \%)$. Não foi observado caso de tumor indiferenciado (G4).

Também preponderou o estágio avançado da doença no momento do diagnóstico e tratamento, tendo o III alcançando quase três quartos do total da amostra $(72,42 \%)$, contra $27,58 \%$ do estágio II. Também aqui não evidenciado caso de do-ença avançada em estágio IV.

Verificou-se também que os tumores com diâmetros maiores que três centímetros eram quase duas vezes mais prevalentes que os menores que isso. Os tumores tiveram freqüência de distribuição mais acentuada nos dois terços inferiores do esôfago, sendo o terço inferior ligeiramente mais prevalente sob o médio $(51,73 \%$ e $44,83 \%$, respectivamente). Identificou-se apenas um caso de localização em terço superior.

A imunorreatividade positiva da amostra foi de $96,55 \%$ (26/29) para o Ki-67 e 96,55\% (28/29) para a Caspase-3. A expressão média do índice de marcagem da Caspase-3 foi cerca de $20 \%$ maior que a obtida para o Ki-67, com índices médios respectivos de 86,06 $\pm 16,41$ (variando de 47,09 a 99,43 ) e 62,05 $\pm 34,83$ (com varia-ção de 5,67 a 96,02).

A imunomarcação pelo Ki-67 foi restrita ao núcleo tanto das células não neo-plásicas quanto das neoplásicas, marcando mais intensamente nestas últimas. As células não neoplásicas com marcação positiva eram em menor número e somente aquelas restritas à camada basal ou para basal. Observou-se heterogeneidade de marcação do Ki-67.

A zona periférica dos núcleos celulares foi mais intensamente marcada com distribuição difusa nos casos poucos diferenciados, que nos bem e moderadamente diferenciados.

Na Tabela 1 estão apresentados os resultados de médias, medianas, valores mínimos, valores máximos e desviospadrão dos índices de expressões dos marcadores Ki-67 e Caspase-3.

Quando se estratificaram as freqüências de expressões dos marcadores em estudo em unidades de dezenas, observou-se maior tendência de expressão do Ki-67 entre as dezenas de oito e nove, perfazendo $61,54 \%$ dos casos $(\mathrm{n}=16)$ e entre as dezenas nove e dez, para a Caspase-3, com percentual de 57,14\% (n=16) (Figuras 1 e 2).
TABELA 1 - Estatísticas descritivas das expressões dos marcadores

\begin{tabular}{lrrrrrc}
\hline Variável & n(29) & Média & Mediana & Mínimo & Máximo $\begin{array}{c}\text { D e s vi o- } \\
\text { padrão }\end{array}$ \\
\hline Índice Ki-67 & $26(89,65 \%)$ & 62,05 & 82,03 & 05,67 & 96,02 & 34,83 \\
Índice Caspase-3 & $28(96,55 \%)$ & 86,06 & 95,18 & 47,09 & 99,43 & 16,41 \\
\hline
\end{tabular}

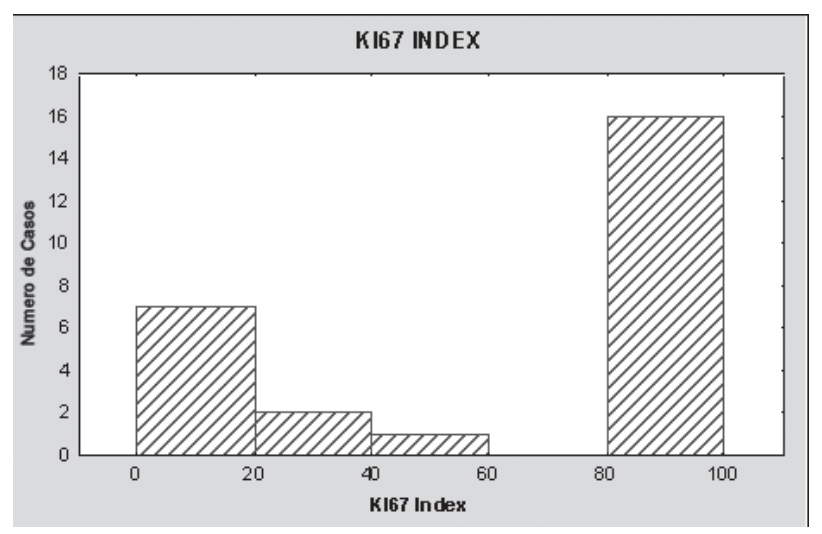

FIGURA 1- Distribuição das frequências dos índices do Ki-67

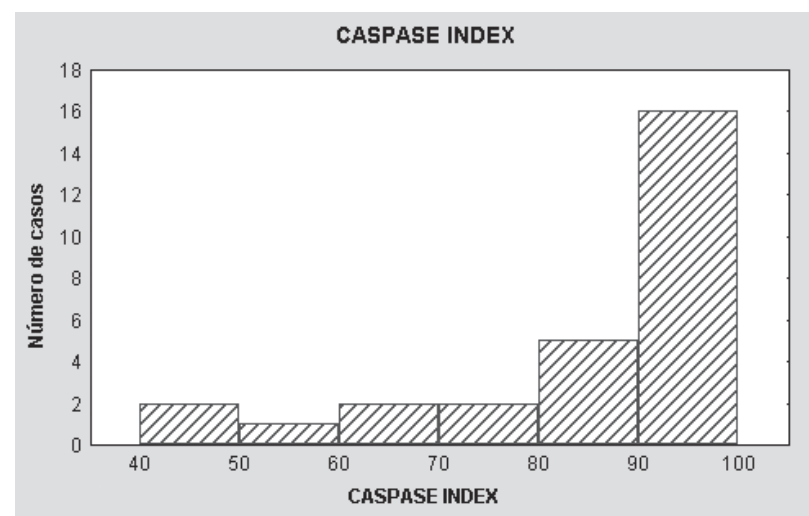

FIGURA 2 - Distribuição das frequências dos índices da Caspase-3

\section{Sexo versus expressões dos marcadores}

Para cada um dos marcadores, testou-se a hipótese nula de que os resultados são iguais para pacientes do sexo masculino e para o feminino, versus a hipótese alternativa de resultados diferentes.

Considerando-se a prevalência de cerca de cinco vezes mais elementos do sexo masculino sobre o feminino, verificouse tendência de expressão média do Ki-67 de quase $20 \%$ a mais do sexo masculino quando comparada com o feminino (64,91\% 46,34\%) sem significância estatística. Já para a Caspase-3, percebeu-se que os índices médios de marcagens são similares para os sexos $(86,21 \%$ / 85,15\%), também sem significância estatística (valores de P maiores do que 0,05 ).

Na Tabela 2 são apresentadas às estatísticas descritivas em relação aos sexos.

\section{Correlação entre os índices dos marcadores}

Para avaliar o grau de associação entre as expressões dos marcadores, foi estimado o coeficiente de correlação entre os índices do KI-67 e Caspase-3. Testou-se a hipó- 
TABELA 2 - Sexo versus índices de expressões dos marcadores

\begin{tabular}{lcccccccc}
\hline Variável & Sexo & n & Média & Mediana & Mínimo & Máximo & $\begin{array}{c}\text { Desvio } \\
\text { padrão }\end{array}$ & $\begin{array}{c}\text { Valor } \\
\text { de p* }\end{array}$ \\
\hline Índice & Masculino & 22 & 64,91 & 84,73 & 5,67 & 96,02 & 35,25 & 0,471 \\
Ki- 67 & Feminino & 04 & 46,34 & 47,34 & 8,19 & 82,48 & 32,02 & \\
\hline Índice & Masculino & 24 & 86,21 & 95,18 & 47,09 & 99,25 & - & 0 \\
Caspase-3 & Feminino & 04 & 85,15 & 90,47 & 60,23 & 99,4 & 18,11 & 0,825 \\
\hline
\end{tabular}

NOTA: (*)Teste não-paramétrico de Mann-Whitney

tese nula de ausência de correlação entre as expressões dos marcadores, versus a alternativa de existência de correlação. Observou-se que há correlação entre os índices pesquisados $(\mathrm{r}=0,41)$ verificado pelo método estatístico de Spearman $(P=0,032)$. A Figura 3 mostra a distribuição espacial desta correlação.

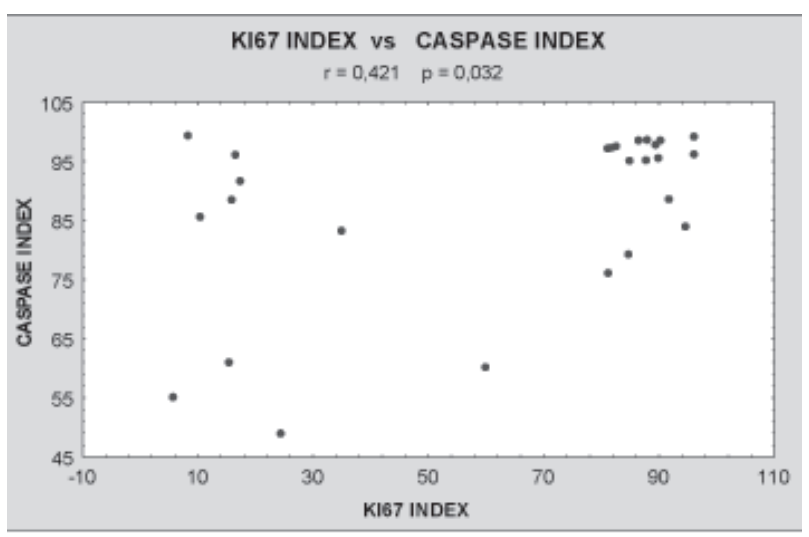

FIGURA 3 - Organização espacial da correlação entre os índices de marcagens do Ki-67 e Caspase-3

\section{Diferenciação tumoral versus expressão dos mar- cadores}

Para cada um dos marcadores, testou-se a hipótese nula de que os resultados são iguais para CCEE pouco diferenciado, moderadamente diferenciado e bem diferenciado, versus a hipótese alternativa de resultados diferentes. $\mathrm{Na}$ Tabela 3 são apresentados às estatísticas descritivas (média, mediana, valor mínimo, valor máximo e desvio-padrão) e os valores de $\mathrm{P}$ dos testes estatísticos.

TABELA 3 - Diferenciação tumoral versus expressões dos marcadores

\begin{tabular}{lcccccccc}
\hline Variável & $\begin{array}{c}\text { Diferenciação } \\
\text { tumoral* }^{*}\end{array}$ & n & Média & Mediana & Mínimo & Máximo & $\begin{array}{c}\text { Desvio } \\
\text { padrão }\end{array}$ & $\begin{array}{c}\text { Valor } \\
\text { de } \mathbf{p}^{* * *}\end{array}$ \\
\hline Índice & Pouco & 03 & 35,76 & 15,32 & 10,39 & 81,58 & 39,75 & \\
KI-67 & Moderada & 18 & 70,16 & 87,06 & 15,80 & 96,02 & 31,44 & 0,047 \\
& Bem & 05 & 48,63 & 59,84 & 5,67 & 84,83 & 39,41 & \\
\hline \multirow{2}{*}{ Índice } & Pouco & 03 & 81,34 & 85,67 & 61,07 & 97,29 & 18,49 & \\
Caspase-3 & Moderada & 20 & 88,82 & 95,88 & 47,09 & 99,25 & 15,28 & 0,471 \\
& Bem & 05 & 77,84 & 79,30 & 55,12 & 99,43 & 19,96 & \\
\hline
\end{tabular}

$(*)$ Pouco diferenciado, moderadamente diferenciado ou bem diferenciado

(**) Teste não-paramétrico de Kruskal-Wallis

Em relação à expressão do índice da Caspase-3, o resultado do teste estatístico indicou a não rejeição da hipótese nula no nível de significância de 5\% (valor de
$\mathrm{P}$ maior do que 0,05). Sendo assim, para esse marcador, não se pode afirmar que existe diferença estatisticamente significativa entre os níveis de diferenciação do carcinoma epidermóide.

Para os índices do Ki-67, o resultado do teste estatístico indicou a rejeição da hipótese nula no nível de significância de $5 \%(P=0,047)$. Desta forma, pode-se afirmar que existe diferença significativa entre os três níveis de diferenciação do carcinoma epidermóide em relação à expressão do índice do Ki-67 com percentuais médios de 35,76\%, $70,16 \%$ e $48,76 \%$, respectivamente para os graus pouco, mode-radamente e bem diferenciados. Para identificar essas diferenças, os níveis foram comparados dois a dois.

$\mathrm{Na}$ comparação de carcinomas pouco diferenciados com os moderadamente diferenciados, o resultado do teste indicou que existe diferença significativa $(P=0,044)$. $\mathrm{O}$ mesmo não acontece quando se compara os carcinomas pouco diferenciados com os bem diferenciados $(P=0,881)$, e os moderadamente diferenciados com os bem diferencia$\operatorname{dos}(P=0,074)$.

Observando-se os valores de médias e medianas na Tabela 3, percebe-se que carcinomas pouco diferenciados apresentam resultados mais baixos de expressão do índice Ki-67 quando comparados com carcinomas moderadamente ou bem diferenciados.

Estadio tumoral versus expressões dos marcadores

Apesar da expressão média ligeiramente superior no estágio III em relação aos IIA e IIB tanto para o índice do Ki-67 (III 71,15\%; IIA e IIB 52,95\%), quanto para a Caspase-3 (III 87,60\%; IIA e IIB 84,51\%), não foram evidenciadas diferenças significantes entre os grupos.

Na Tabela 4 são apresentadas às estatísticas descritivas com as expressões dos marcadores com relação aos estadios tumorais.

TABELA 4 - Estadio tumoral versus expressões dos marcadores

\begin{tabular}{lcccccccc}
\hline Variável & $\begin{array}{c}\text { Estadio } \\
\text { tumoral }\end{array}$ & $\mathbf{n}$ & Média & Mediana & Mínimo & Máximo & $\begin{array}{c}\text { Desvio } \\
\text { padrão }\end{array}$ & $\begin{array}{c}\text { Valor } \\
\text { de p* }\end{array}$ \\
\hline Índice & IIA IIB & 13 & 52,95 & 59,84 & 08,10 & 95,99 & 36,31 & 0,201 \\
Ki-67 & III & 13 & 71,15 & 84,83 & 05,67 & 96,02 & 32,09 & \\
\hline Índice & IIA IIB & 14 & 84,51 & 92,09 & 47,09 & 99,43 & 17,07 & 0,635 \\
Caspase-3 & III & 14 & 87,60 & 95,17 & 49,01 & 99,25 & 16,22 & \\
\hline
\end{tabular}

NOTA: $\left({ }^{*}\right)$ Teste não-paramétrico de Mann-Whitneys

\section{Grau de profundidade da lesão versus expressões dos marcadores}

Não mostraram ter significância estatística as expressões dos marcadores quanto se considerou o grau de profundidade da lesão na parede do órgão. Mesmo tendo a casuística cerca de três vezes mais tumores imunoreativos ao Ki-67 e Caspase-3 daqueles que alcançaram à túnica adventícia ( $\mathrm{n}=20$ e $\mathrm{n}=21$ ) quando compa-rados aqueles que atingiram apenas as túnicas musculares ( $\mathrm{n}=06$ e $\mathrm{n}=07)$, suas expressões médias foram semelhantes $(62,16 \%$ / $61,70 \% ; 88,91 \%$ / 83,30\%, respectivamente para o Ki-67 e Caspase-3).

Na Tabela 5 são apresentados às estatísticas descritivas 
do comportamento distributivo da amostra em relação à profundidade da lesão.

TABELA 5 - Grau de profundidade da lesão versus expressões dos marcadores

\begin{tabular}{|c|c|c|c|c|c|c|c|c|}
\hline Variável & $\begin{array}{l}\text { Profun- } \\
\text { di da d e } \\
\text { da lesão }\end{array}$ & $\mathbf{n}$ & Média & Mediana & Mínimo & Máximo & $\begin{array}{c}\text { Desvio } \\
\text { padrão }\end{array}$ & $\begin{array}{l}\text { Valor } \\
\text { de p* }\end{array}$ \\
\hline \multirow{2}{*}{$\begin{array}{l}\text { Índice } \\
\text { Ki-67 }\end{array}$} & $\mathrm{T} 2$ & 06 & 61,70 & 70,43 & 15,32 & 89,79 & 31,00 & \multirow{2}{*}{0,744} \\
\hline & $\mathrm{T} 3$ & 20 & 62,16 & 83,55 & 5,67 & 96,02 & 36,66 & \\
\hline \multirow{2}{*}{$\begin{array}{l}\text { Índice } \\
\text { Caspase-3 }\end{array}$} & $\mathrm{T} 2$ & 07 & 77,49 & 83,30 & 47,09 & 97,84 & 21,05 & \multirow{2}{*}{0,208} \\
\hline & T3 & 21 & 88,91 & 95,21 & 49,01 & 99,43 & 14,01 & \\
\hline
\end{tabular}

NOTAS: $(*)$ Teste não-paramétrico de Mann-Whitney

\section{Comprometimento linfonodal versus expressões dos marcadores}

Quando analisados os índices médios de marcagens expressos em relação ao comprometimento linfonodal, verificou-se os maiores índices para a Caspase- $3(\mathrm{~N} 0=51,28$ e N1=69,95) em relação ao Ki-67 (N0=83,50 e N1=87,98) e com valores médios sempre maiores para os casos em que há comprometimento linfonodal se comparado com os casos livres da doença. Não foi evidenciada significância nas expressões das proteínas pesquisadas entre os casos de linfonodos com e sem acometimento pela doença. $\mathrm{Na}$ Tabela 6 são visualizados os dados descritivos relativos ao comprometimento linfonodal.

TABELA 6 - Linfonodos versus expressão dos marcadores

\begin{tabular}{lcccccccc}
\hline Variável & $\begin{array}{c}\text { Linfono- } \\
\text { do }\end{array}$ & n & Média Mediana & Mínimo & Máximo & $\begin{array}{c}\text { Desvio } \\
\text { padrão }\end{array}$ & $\begin{array}{c}\text { Valor } \\
\text { de p* }\end{array}$ \\
\hline Índice & N0 & 11 & 51,28 & 59,84 & 08,19 & 95,99 & 37,60 & 0,164 \\
KI-67 & N1 & 15 & 69,95 & 84,83 & 05,67 & 96,02 & 31,61 & \\
\hline Índice & N0 & 12 & 83,50 & 92,10 & 47,09 & 99,43 & 18,08 & 0,568 \\
Caspase-3 & N1 & 16 & 87,98 & 95,18 & 49,01 & 99,25 & 15,36 & \\
\hline
\end{tabular}

NOTAS: $\left({ }^{*}\right)$ Teste não-paramétrico de Mann-Whitney

\section{DISCUSSÃO}

A avaliação semi-quantitativa e qualitativa das imunoreações positivas sob visão humana é trabalhosa, tediosa e subjetiva. A dificuldade para contar o número total de núcleos ou células imunomarcadas é bem conhecida de todos pelo método manual. Assim o processo manual de contagem pode envolver quantificação para mais ou para menos, consome tempo e energia, não é objetiva e pode variar conforme cada observador ou entre observadores diferentes. Também pode ser afetada pela experiência e outros fatores psicológicos do patologista. Sem contar que as imagens podem perder a qualidade com o passar do tempo, onde os núcleos ou células não podem mais ser contados em um curto período de tempo.

A quantificação computadorizada envolve a captura de imagem no campo microscópico e processamento da imagem tem significativas vantagens sobre a contagem visual do método manual. As vantagens são que as imagens capturadas e salvas podem ser armazenadas, tratadas e interpretadas quando convier ao observador e não há necessi- dade de recaptura quando se deseja novas investigações futuras. Por outro lado, como desvantagens, enumeram-se as dificuldades de focar a imagem, controle adequado da intensidade de luz e limitação de magnificação da imagem, que podem ser cuidadosamente ajustados.

O software Immuno foi o usado na análise de imagem para a leitura da imunorreatividade das proteínas do núcleo (Ki-67) e do citoplasma (Caspase-3) imunomarcados positivamente utilizando a plataforma do SAMBA. Este leitor e analisador de imagem vem sendo utilizado na quantificação da expressão de inúmeras proteínas celulares, como em CHAPIN et al(1989) que investigaram atividade proliferativa de carcinomas endometriais mediada pelo Ki-67, Van, et al. ${ }^{25}$, nos estudos da atividade proliferativa medida pelo Ki-67 em endocérvices uterina e Minimo, et al. ${ }^{15}$ avaliando atividade em tumores ampulares.

Após extensa revisão na literatura médica, não foi identificado estudo que medisse a expressão da proteína Caspase-3 pelo método semi-automatizado de análise de imagem, assim como só foram identificados dois estudos pelo referido método medindo a expressão da proteína Ki-67.

Por outro lado, na mesma revisão bibliográfica realizada, ficou evidente a correlação positiva que há entre os resultados obtidos pelos dois métodos (manual e semiautomatizado de análise computadorizada de imagem) comumente utilizados nos estudo de quantificações de proteínas celulares.

As tentativas de melhor indicar tratamento ou predizer prognóstico adequados para os pacientes com CCEE têm esbarrado na dificuldade de estadiar o mais fielmente a doença. Isto advém do dilema que vivem os médicos com o fato bem conhecido de pacientes portadores de tumores em determinado estágio da doença, histologicamente similares, e resultados clínicos diferentes quanto à resposta ao tratamento instituído ou a forma de evolução da doença. Alguns pacientes viverão sem evidência da doença e outros morrerão de sua doença em períodos de tempo variáveis ${ }^{17}$.

Os estadiamentos tumorais geralmente se valem do auxílio das imagens para identificar as lesões maiores dentro ou fora dos sítios primários tumorais, das alterações de algumas proteínas plasmáticas e da avaliação de características histopatológicas do tumor como o tamanho do tumor, profundidade da invasão do tumor, do comprometimento linfonodal ou linfático.

Esta heterogeneidade de resultados clínicos alertou para a necessidade de refinar os estadiamentos tumorais, não somente com o aprimoramento das técnicas radiológicas de imagens ou do aprofundamento dos conhecimentos histopatológicos. Com o aprimoramento dos conhecimentos do comportamento biológico tumoral, percebeu-se que além dos fatores genéticos sabidamente envolvidos, alterações sofridas pelas proteínas que controlam o ciclo celular são responsáveis pelos resultados clínicos tão díspares ${ }^{26}$.

Uma das principais alterações identificadas na tumorigênese é a taxa de mitose. A alta de mitose é mais comum nos tumores de natureza maligna que benigna e é um dos parâmetros de identificação entre estas duas entidades, 
assim como traz informações prognósticas relevantes. Tumores com altos índices mitóticos estão as-sociados com pior prognóstico, pior resposta terapêutica quando comparados com os com poucas mitoses ${ }^{26}$.

Um dos meios de medir o índice mitótico é através da relação entre as células que estão em divisão e aquelas que se encontram em repouso celular. Este coeficiente é chamado de índice proliferativo.

O controle celular da mitose é realizado por grupos específicos de proteínas que regulam o ciclo celular, dentre elas a proteína Ki-67. Outro processo complexo envolvido no equilíbrio dinâmico da biologia celular normal é a morte programada celular ou apoptose. Este processo também é controlado por grupos específicos de proteínas, sendo as mais conhecidas o grupo das Caspases ${ }^{20}$.

Utilizou-se no presente estudo a pesquisa da Caspase-3 por ser uma das proteínas efetoras da apoptose mais bem estudada e que mais se relaciona com o controle da morte celular.

A proteína Ki-67 começa a ser expressa na fase $\mathrm{S}$, elevando seu nível durante as fases S e G2, alcançando o seu nível mais elevado durante a mitose. Após a divisão as células retornam a fase $\mathrm{G} 1$, quando o nível desse antígeno decresce progressivamente. Sua expressão ocorre em quase todas as fases do ciclo celular, exceto pela fase $\mathrm{G} 0 \mathrm{em}$ que as células estão em repouso ${ }^{22}$.

$\mathrm{O}$ perfil epidemiológico referente à idade e sexo dos pacientes portadores de CCEE no presente estudo é semelhante aos referidos por outras publicações na literatura $^{7,16,19}$, como a predominância de pacientes do sexo masculino $(82,7 \%)$ e com idade superior a 50 anos (idade média de 58,7 anos).

Talvez por se tratar de um estudo retrospectivo, os demais elementos epidemiológicos relacionados (hábitos de vida, raça, uso abusivo de álcool e tabaco) não puderam ser avaliados durante a coleta dos dados, por se encontrarem bastante incompletos nos prontuários pesquisados.

Quase toda amostra teve imunorreativa positiva ao Ki-67(89,65\%). A expressão do índice médio do marcador variou amplamente na revisão de literatura segundo a origem do tecido examinado.

No presente estudo, encontrou-se índice médio de $62,05 \pm 34,83$ (variando de 5,67 a 96,02) para os 26 pacientes imunorreativos positivos que se encontrava dentro dos intervalos médios identificados publicados em diferentes artigos.

A ampla variação de expressão do índice médio do Ki-67 ficou evidente na revisão bibliográfica realizada, tanto nos índices médios obtidos pelo SAMBA quanto pelo manual. Pelo método manual imunoistoquímico realizados em amostras tumorais de CCEE foram obtidos os seguintes índices médios: $71 \%$, Takeuchi, et al. ${ }^{23} ; 22,6 \%$ Huang et al. ${ }^{10}$ e $45 \%$ Ikeda et al. ${ }^{11}$.

Quando foi comparado à expressão do KI-67 com fatores clínico-patológicos considerados não houve correlação, exceto para o grau de diferenciação celular, único fator de correlação positiva encontrado. Estes achados são corroboradas por outros autores em leitura manual ${ }^{10,11,23} \mathrm{e}$ pelo SAMBA $2,3,6,13,18$.
Apesar da diferença significante entre as expressões do marcador Ki-67 entre graus histológicos, verificou-se maior expressão média para o grau moderadamente diferenciado $(70,16 \%$, variando de 15,80 a $96,02 \%)$ e o menor índice médio para o grau pouco diferenciado $(35,76 \%$, variando de 10,39 a 81,58 ).

A distribuição da expressão do marcador nos graus histológicos encontrada neste estudo diverge parcialmente dos dados da literatura. Os resultados da literatura mostram que o índice de expressão cresce em proporção linear do grau bem diferenciado ao indiferenciado. Aqui foram encontrados índices maiores para os graus moderadamente diferenciados, seguido pelo bem e pouco diferenciados. Isto talvez possa ser justificado pelo casuística reduzida da amostra de CCEE pouco diferenciado (apenas três casos) quando comparado com os graus moderadamente (18 ca-sos) e bem diferenciados (cinco). Ou também pelas alterações irreversíveis ocorridas nas proteínas celulares consequentes aos processos de fixação do material biológico (tempo de fixação, por exemplo) que não foram controlados e a heterogeneidade de distribuição da proteína dentro do tumor ${ }^{8}$.

A expressão alterada do Ki-67 ocorre em uma ampla variedade de tumores humanos. A frequente tentativa de associação de sua expressão com características clínicopatológicas das neoplasias indica papel importante desta proteína na tumorigênese. $\mathrm{O}$ elevado índice de marcagem para o Ki-67 encontrado nas amostras de CCEE (índice médio de $62,05 \%$ ) neste estudo sugere que a forte expressão desta proteína seja um evento - entre os vários outros existentes -, que atua de forma determinante, associado ou isoladamente com outras proteínas reguladoras do ciclo celular no desenvolvimento do câncer esofágico.

A proteína Caspase-3 foi quase integralmente imunomarcada positivamente $(96,55 \%$ da amostra), considerando-se como positivo apenas a presença da cor acastanhada citoplasmática independente de intensidade. Esta percentagem de posi-tividade da amostra é bem superior à encontrada por Chang et al. ${ }^{1}$, de 19\% em sua série de 118 casos de CCEE, considerando positivo a presença de pelos menos 10 células imunomarcadas; de Tanimoto et al. ${ }^{24}$, $44 \%$ dos casos con-siderando pelo menos 3\% de células imunomarcadas em carcinomas epidermóides da região da cabeça e pescoço e Hsia et al. ${ }^{9}, 60 \%$ de positividade para o tipo não invasivo e $4 \%$ para o tipo invasivo nos 40 casos de CCEE analisados, considerando positivo a existência de pelo menos $25 \%$ de células imunomarcadas e Kurabayashi et al. ${ }^{12}, 55,4 \%$ dos casos.

Não foi encontrado correlação entre a distribuição da expressão da proteína Caspase-3 com os aspectos clínicopatológicos considerados. Este resultado é corroborada pelo de Hsia et al. ${ }^{9}$ em mensuração manual de amostra de 40 casos de CCEE. Neste estudo, 9 casos (22,5\%) não marcaram para a proteína e obteve marcação positiva em fraca em $7(17,5 \%)$, moderada em $7(17,5 \%)$ e forte em $17(42,5 \%)$.

Múltiplos fatores são responsáveis pela modulação do crescimento tumoral. Ultimamente se tem valorizado muito 
que a perda do controle do volume tumoral é devida ao desequilíbrio da relação dinâmica apoptose e proliferação celular 5 .

Com a análise estatística verificou-se correlação positiva entre os marcadores mostrando que a variação de uma proteína é acompanhada pela variação da outra no mesmo sentido, proporcionalmente.

Até o presente momento permanece o estadiamento histopatológico como elemento mais significante na escolha de um tratamento ou como elemento de prognóstico. Entretanto, tem-se desenvolvido interesse no estudo de marcadores biológicos que venham auxiliar e ajudar nesta escolha. $\mathrm{O}$ futuro parece promissor em relação aos marcadores tumorais. Contudo, as pesquisas ainda são incipientes em relação ao universo a ser estudado e muito ainda temse que caminhar para elucidar o papel dessas proteínas na tumorigênese e qual o melhor meio de sua detecção, va-lor de diagnóstico e de prognóstico.

\section{CONCLUSÕES}

1. A prevalência média das expressões citofotométricas pelo SAMBA para a proteína Ki-67 foi de $62,05 \%$ e de $86,06 \%$, para a Caspase-3;

2. Não houve correlação dos índices de marcagens proliferativo e apoptótico com as características clínicopatológicas analisadas (idade, sexo, estadio, diferenciação celular, grau de profundidade da lesão e comprometimento linfonodal)

Silva GP, Malafaia O, Cuenca RM, Ribas-Filho JM, Nassif PAN, Ribas CAPM, Zeve JLM. Clinicopathologic significance of the Ki-67 and Caspase-3 cytophotometric expressions in the esophageal squamous cell carcinomal. ABCD Arq Bras Cir Dig. 2008;21(2):77-84

ABSTRACT - Background - The esophageal squamous cell carcinoma treatment strategy is still based on the tumor staging, where tumor histopathologic charac-teristics are the major determinants. In parallel, studies have been developed in order to better understand the tumor biology using immunohistochemical meth-ods with manual quantification evaluating the proliferative and apoptotic activi-ties of the cells. The disadvantages related to the manual method rose the de-velopment of computerized ways to do the image analysis. Objectives - To verify the expressions of the markers Ki-67 (proliferative) and Caspase-3 (apoptotic) and to correlate them with the clinic and pathologic characteristics of the tumor. Methods - Twenty-nine paraffin embedded blocks were studied, each one con-taining tissue samples from patients with esophageal squamous cell carcinoma submitted to esophagectomies. The clinic and pathological data were obtained from histopathologic informations and from medical records. The slides were prepared following the routine immunohistochemical method until the point to utilize the specific antibodies (MIB-1 and CPP32). Positive quantification of the immunoreactivity to the proteins Ki-67 and Caspase-3 was performed by the software for computerized image analysis SAMBA (Systeme d' Analyse Micro-photometrique a Balayage Automatique). Statistical analysis was done having $\mathrm{P}<0.05$ considered significant. Results - There was predominance of males (82.7\%); age over 50 years; moderately differentiated tumors (68.98\%); tumor stage III (72.42\%); diameter of lesions $>3 \mathrm{~cm}$; and lesions located in the lower third of the organ. The mean score indexes found were $62.05 \%$ for Ki-67 and $86.06 \%$ for Caspase- 3 and there was no correlation with the clinic or pathologi-cal characteristics as gender, age and tumor staging. There was significant dif-ference of Ki-67 expression among the histological grades $(P=0.047)$ and corre-lation between the evaluated indexes $(\mathrm{r}=0.41$ and $\mathrm{P}=0.032)$. Conclusion - The protein expressions were high and the Caspase-3 protein activity was higher than the Ki-67, without correlation with clinic or pathological characteristics as gender, age, tumor staging, grade of lesion depth and lymph node invasion.

HEADINGS - Ki-67. Caspase-3. Image cytometry. Esophageal carcinoma.

\section{REFERÊNCIAS}

1. Chang HY, Yang X. Proteases for cell suicide: functions and regulation of Caspases. Microbiol Mol Biol Rev. 2000 Dec;64(4):821-46.

2. Charpin C, Andrac L, Lavaut MN, Andonian C, Fraterno M, Devictor B, Perez-Castillo A, Bonnier P, Piana L. Image cytometry of aneuploidy, growth fraction (MoAb Ki-67) and hormone receptors (ER, PR) immunocytochemical assays in breast carcinomas. Anal Cell Pathol. 1990 Oct;2(6):357-71.

3. Costes V, Marty-Ané C, Picot MC, Serre I, Pujol JL, Mary H, Baldet P. Typical and atypical bronchopulmonary carcinoid tumors: a clinicopathologic and KI-67-labeling study. Hum Pathol. 1995 Jul;26(7):740-5.

4. Daly JM, Karnell LH, Menck HR. National Cancer Data Base report on esophageal carcinoma. Cancer. 1996 Oct 15;78(8):1820-8.

5. Depraetere V, Golstein P. Dismantling in cell death: molecular mechanisms and relationship to Caspase activation. Scand J Immunol. 1998 Jun;47(6):52331 .

6. Devictor B, Bonnier P, Piana L, Andrac L, Lavaut MN, Allasia C, Charpin C. c-myc protein and $\mathrm{Ki}-67$ antigen immunodetection in patients with uterine cervix neoplasia: correlation of microcytophotometric analysis and histological data. Gynecol Oncol. 1993 Jun;49(3):284-90.

7. Guttman D, Stern Y, Shpitzer T, Ulanovski D, Druzd T, Feinmesser R. Expression of MMP-9, TIMP-1, CD-34 and factor-8 as prognostic markers for squamous cell carcinoma of the tongue. Oral Oncol. 2004 Sep;40(8):798803.

8. Hall PA, Levison DA. Review: assessment of cell proliferation in histological material. J Clin Pathol. 1990 Mar;43(3):184-92.

9. HSIA, JY.; CHEN, CY.; CHEN, CJ.; CHEN, CP.; SHAI, SE.; YANG, SS.; CHUANG, CY.; WANG, PY. W.; MIAW, CY. Prognostic significance of Caspase-3 expression in primary resected esophageal squamous cell carcinoma. EJSO, v. 29 , p. 44-48, 2003.
10. Huang JX, Yan W, Song ZX, Qian RY, Chen P, Salminen E, Toppari J. Relationship between proliferative activity of cancer cells and clinicopathological factors in patients with esophageal squamous cell carcinoma. World J Gastroenterol. 2005 May 21;11(19):2956-9.

11. Ikeda G, Isaji S, Chandra B, Watanabe M, Kawarada Y. Prognostic significance of biologic factors in squamous cell carcinoma of the esophagus. Cancer. 1999 Oct 15;86(8):1396-405.

12. Kurabayashi A, Furihata M, Matsumoto M, Ohtsuki Y, Sasaguri S, Ogoshi S. Expression of Bax and apoptosis-related proteins in human esophageal squamous cell carcinoma including dysplasia. Mod Pathol. 2001 Aug;14(8):741-7.

13. MARINAZZI, M;ZAMPIERI, A.; MARTINAZZI, S.; CRIVELLI, F.; MAURI, MF. CA-LANDRA, C. [Proliferative activity of stage I testicular neoplasms: evaluation by im-age analysis of immunoreactive MIB-1. Pathologica, v. 90, n. 6, p. $783-7,1998$.

14. MESSMANN, H. Squamous cell cancer of the oesophagus. Best Practice \& Re-search Clinical Gastroenterology, vol. 15, No. 2, p. 249 265 , 2001.

15. MINIMO, C.; McCUE,PA.;PINDZOLA, A.BENNAM,J.; BIBBO, M. Role of computed quantitation of immunohistochemical staining of Ki-67 antigen in diagnosing ampul-lary lesions. Anal Quant Cytol Histol. v. 18, n. 5, p. 400-4, 1996.

16. Muñoz N. Epidemiological aspects of oesophageal cancer. Endoscopy. 1993 Nov;25(9):609-12.

17. Fenoglio-Preiser CM. Selection of appropriate cellular and molecular biologic diagnostic tests in the evaluation of cancer. Cancer. 1992 Mar 15;69(6 Suppl):1607-32.

18. Querzoli P, Albonico G, Ferretti S, Rinaldi R, Magri E, Indelli M, Nenci I. MIB-1 proliferative activity in invasive breast cancer measured by image analysis. J Clin Pathol. 1996 Nov;49(11):926-30. 
19. Ribeiro Pinto LF, Teixeira Rossini AM, Albano RM, Felzenszwalb I, de Moura Gallo CV, Nunes RA, Andreollo NA. Mechanisms of esophageal cancer development in Brazilians. Mutat Res. 2003 Nov;544(2-3):365-73.

20. Rudin CM, Thompson CB. Apoptosis and disease: regulation and clinical relevance of programmed cell death. Annu Rev Med. 1997;48:267-81.

21. Schrump D, Altorki N, Forastiere A. Cancer of the esophagus. In: DeVita VT Jr, Hellman S, Rosenberg SA, eds. Cancer: Principles and Practice of Oncol-ogy, Sixth Edition. Philadelphia, PA: Lippincott-Williams \& WilKins,p.1319-1342, 2001

22. Seigneurin D, Guillaud P. Ki-67 antigen, a cell cycle and tumor growth marker. Pathol Biol (Paris). 1991 Dec;39(10):1020-8.

23. Takeuchi H, Ozawa S, Ando N, Kitagawa Y, Ueda M, Kitajima M. Cell-cycle regulators and the Ki-67 labeling index can predict the response to chemoradiotherapy and the survival of patients with locally advanced squamous cell carcinoma of the esophagus. Ann Surg Oncol. 2003 Aug;10(7):792-800.
24. Tanimoto T, Tsuda H, Imazeki N, Ohno Y, Imoto I, Inazawa J, Matsubara O Nuclear expression of cIAP-1, an apoptosis inhibiting protein, predicts lymph node metastasis and poor patient prognosis in head and neck squamous cell carcinomas. Cancer Lett. 2005 Jun 16;224(1):141-51.

25. van Hoeven KH, Ramondetta L, Kovatich AJ, Bibbo M, Dunton CJ. Quantitative image analysis of MIB-1 reactivity in inflammatory, hyperplastic, and neoplastic endocervical lesions. Int J Gynecol Pathol. 1997 Jan;16(1):15-21.

26. Ward LS. Entendendo o processo molecular da tumorigênese. Arq Bras Endocrinol Metab. 2002;46(4):351-60.

27. Zhou G, Li H, Gong Y, Zhao Y, Cheng J, Lee P, Zhao Y. Proteomic analysis of global alteration of protein expression in squamous cell carcinoma of the esophagus. Proteomics. 2005 Sep;5(14):3814-21.

Fonte de financiamento: não há Conflito de interesse: não há Recebido para publicação: 10/11/2007 Aceito para publicação: 12/02/2008

\section{C)

